\title{
Effect of the Technological Status of Small Cow-Calf Farm Producers on the Induction to Resumption of Ovarian Activity of Dual-Purpose Cattle Raised under Topical Conditions
}

\author{
Henry Velázquez Penagos ${ }^{1}$, Leticia Galindo Rodríguez², Manuel Barrientos Morales³, \\ Carlos Salvador Galina Hidalgo ${ }^{1}$, Martín Guillermo Maquivar Linfoot ${ }^{4}$, Felipe Montiel Palacios ${ }^{3}$ \\ ${ }^{1}$ Departamento de Reproducción, Facultad de Medicina Veterinaria y Zootecnia, UNAM, CDMX, México \\ ${ }^{2}$ Centro de Enseñanza, Investigación y Extensión en Ganadería Tropical, Facultad de Medicina Veterinaria y Zootecnia, \\ Universidad Nacional Autónoma de México, Martínez de la Torre, Veracruz, México \\ ${ }^{3}$ Facultad de Medicina Veterinaria y Zootecnia, Universidad Veracruzana, Veracruz, México \\ ${ }^{4}$ Department of Animal Sciences, Washington State University, Pullman, Washington DC, USA \\ Email: fmontiel@uv.mx
}

How to cite this paper: Penagos, H.V., Rodríguez, L.G., Morales, M.B., Hidalgo, C.S.G., Linfoot, M.G.M. and Palacios, F.M. (2020) Effect of the Technological Status of Small Cow-Calf Farm Producers on the Induction to Resumption of Ovarian Activity of Dual-Purpose Cattle Raised under Topical Conditions. Open Journal of Veterinary Medicine, 10, 195-205.

https://doi.org/10.4236/ojvm.2020.1011017

Received: October 10, 2020

Accepted: November 27, 2020

Published: November 30, 2020

Copyright $\odot 2020$ by author(s) and Scientific Research Publishing Inc. This work is licensed under the Creative Commons Attribution International License (CC BY 4.0).

http://creativecommons.org/licenses/by/4.0/ (c) (i) Open Access

\begin{abstract}
The aim of the present study was to evaluate the impact of the technological level in small-scale dual-purpose cow-calf Bos indicus female operations on the resumption of the ovarian activity post-partum. A total of 13 small scale dual-purpose Bos indicus $\times$ Bos taurus operations were included in this experiment and they were classified according to their technological status as: high technological status (HT), medium technological status (MT) and low technological status (LT). Ninety-three mature cows were treated with either a CIDR (controlled internal drug release device) with estradiol benzoate (CIDR+EB) or alone (CIDR). At day 9 all animals received intravaginally a CIDR for nine days. At day 0, the CIDR was withdrawn and 24 hours later one dose of estradiol benzoate was administered to 51 cows (17 in HT, 17 in MT and 17 in LT), the remaining animals $(n=42)$ did not receive the estradiol benzoate administration (14 in HT, 13 in MT and 15 in LT). Comparisons were performed on serum progesterone concentrations after CIDR treatment. By day 7 after implant withdrawal, the proportion of cows that resume ovarian activity detected by progesterone concentration increased in all technological level farms, no statistical main effect was observed within technological level. By day 17 there was a significant main effect of technological level $(P=0.05)$ on the proportion of animal that resumed the estrous
\end{abstract}


cycles, but neither a main effect of treatment $(\mathrm{P}=0.97)$ nor an interaction between technological level and treatment $(\mathrm{P}=0.98)$. Furthermore, technological level of the farm showed a tendency $(P=0.07)$ to affect that resume the estrous activity, and a significant effect of treatment was observed $(\mathrm{P}=0.005)$ but no interaction between technological level and treatment. The proportion of cows that showed estrus was different across technological level $(P=0.02)$, the highest proportion of cows showing estrus regardless of treatment was in the HT: $90 \%$ (40\% CIDR and 50\% CIDR+EB), MT: 50\% (13.3\% CIDR and $36.7 \% \mathrm{CIDR}+\mathrm{EB})$ and in the LT: $50 \%(18.8 \% \mathrm{CIDR}$ and $31.3 \% \mathrm{CIDR}+\mathrm{EB})$. In conclusion, the combination of a progestogen and estradiol benzoate resulted in a high proportion of cows that were induced to resume the ovarian activity and this treatment was particularly beneficial in the medium and low technological status of the farms.

\section{Keywords}

Cattle, Ovulation, Technological Level, Small Cow-Calf Farm Producers

\section{Introduction}

Small scale operations (less than 100 animals) dominate the landscape of Latin-American countries livestock production. This type of production is characterized by a low input level (capital, technology, nutrition, management and labor) and small to moderate outputs [1] [2] [3]. Small scale dual-purpose cattle producers face several challenges that limit the productivity and reproductive performance and impede the growth and development of the industry. Among these challenges are the environmental factors, genetics and breeds of the animals, nutritional needs, health and the overall management of the animal [4] [5]. Furthermore, some of the most important limitations for these producers is the low reproductive performance showed by the animals resulting in extended calving intervals, prolonged ovarian inactivity after calving, reproductive diseases and increase culling rates in addition to low productivity of the farms [2] [6]. Traditionally, reproductive performance of Bos indicus cattle raised in the tropics is very low and has been attributed to many factors such as poor nutrition, seasonality of the grasses, failure to resume the ovarian activity after parturition, lack of sexual receptivity, and reproductive diseases [7]. Estrous synchronization programs were developed to control the follicular development and set the timing at which a female showed sexual receptivity therefore facilitating the artificial insemination of the females [8] [9]. Additionally, estrous synchronization programs also aim to induce the resumption of estrous cycles after calving which is a feasible approach to improve the reproductive performance of the cows [10]. However, for a small-scale producer, it can be hard and costly to implement these reproductive programs. Another challenge that small-scale cattle producers experience is that most of the synchronization programs have been devel- 
oped in large scale operations with excellent management and technology and not necessarily transferable to the conditions present in small operations and in tropical environments [1] [11]. Finally, in order to induce the resumption of the ovarian activity, it is necessary to include a therapy that involves a progestogen compound either alone or with the application of prostaglandin F2 $\alpha$ or the administration of estradiol benzoate. These regimes have resulted in highly variable rates in the efficacy to induce the resumption of the ovarian activity postpartum [7] [12]. Therefore, the aim of the present study was to evaluate the impact of the technological level in small-scale dual-purpose cow-calf operations on the resumption of the ovarian activity post-partum of Bos indicus cows with an induction program using a CIDR with either the administration of estradiol benzoate or alone.

\section{Material and Methods}

All experimental procedures conducted on the animals were approved by the National Autonomous University of Mexico Animal Care and Use Committee approved in January 2013. A total of 13 small scale dual-purpose Bos indicus $\times$ Bos taurus operations were included in this experiment. These farms were located in the state of Veracruz (southeast of Mexico) with sub-tropical weather, averaging $1108 \mathrm{~mm}$ of annual precipitation and an average temperature of $25.0^{\circ} \mathrm{C}$ and $81 \%$ of humidity.

All farms were classified according to their technological status as: high, medium or low. The definition of the technological status was as follows:

High technological status (HT): Farms implemented improved grazing systems and seeding grass such as Africa star grass (Cynodon plectostachyus), African Bermuda grass (Cynodon nlemfuensis), Pangola grass (Digitaria decumbens), Signal grass (Brachiaria decumbens), with nutritional supplementation at the time of milking, annual preventive veterinary medicine programs (vaccinations and deworming) at the farm and consultation with a veterinarian when a medical treatment is necessary for an animal. Finally, these farms had a computer with health, reproductive and productive records.

Medium technological status (MT): These farms had all the characteristics of a high technological status but not computer or records.

Low technological status (LT): These farms fed their animals with native grazing pastures that included Bahiagrass (Paspalum spp.) and carpet grass (Axonopus spp.) with no supplementation, and lack of preventive veterinary medicine and no veterinarian, and no records are collected.

\subsection{Animals and Treatments}

Ninety-three mature Bos indicus $\times$ Bos taurus cows were used in this experiment, the characteristics of the cows at the beginning of the experiment are shown in Table 1. All cows were treated with either a CIDR with estradiol benzoate (CIDR+EB) or alone (CIDR). Briefly, the body condition score (BCS) in a scale of 1 - 5 (where $1=$ emaciated and $5=$ obese) was recorded at day 9 (day of 
Table 1. The descriptive statistics of the cows from the different levels of technology at the farm at the beginning of the experiment (High technology $=\mathrm{HT}$, Medium technology $=$ MT and Low technology $=$ LT) included in the experiment. Different literal within row significantly differ.

\begin{tabular}{lcccc}
\hline \multicolumn{5}{c}{ Technological status } \\
Variable & HT (n=31) & MT (n=30) & LT (n=32) & P value \\
\hline Age of the cows (years) & $7.09 \pm 2.69$ & $5.48 \pm 1.71$ & $5.81 \pm 1.83$ & 0.08 \\
Number of parturitions/cow (n) & $3.58 \pm 2.15$ & $2.23 \pm 1.35$ & $2.68 \pm 1.83$ & 0.11 \\
Postpartum days & $67.74 \pm 11.53$ & $67.1 \pm 7.71$ & $70.03 \pm 10.66$ & 0.62 \\
Body condition score & & & & \\
D-9 & $1.83 \pm 0.32$ & $1.65 \pm 0.23$ & $1.81 \pm 0.32$ & 0.09 \\
D17 & $1.90 \pm 0.32 \mathrm{a}$ & $1.56 \pm 0.31 \mathrm{~b}$ & $10.70 \pm 0.37 \mathrm{~b}$ & 0.01 \\
\hline
\end{tabular}

CIDR insertion), and day 17. All animals received intravaginally a controlled internal drug release devise (CIDR, containing $1.9 \mathrm{~g}$ of progesterone; Zoetis Animal Health) for nine days. At day 0, the CIDR was withdrawn and 24 hours later $1 \mathrm{mg}$ of estradiol benzoate (Estradiol benzoate; Zoetis Animal Health) was administered intramuscularly to 51 cows (17 in HT, 17 in MT and 17 in LT), the remaining animals $(\mathrm{n}=42)$ did not receive the estradiol benzoate administration $(14,13$ and 15 in HT, MT and LT, respectively). At day 0 the calves were separated from their dams for 48 hours. The characteristics of the animals are presented in Table 1.

\subsection{Reproductive and Productive Evaluations}

Evaluation of the reproductive tract was be performed using an ultrasound (Aloka SDD 500; Aloka CO. LTD, Japan) screening of the ovarian structures performed at the day of the CIDR insertion. During this evaluation, the diameter of the dominant follicle and the presence of Corpus luteum were recorded [13] [14]. Additionally, blood samples (approximately $10 \mathrm{~mL}$ ) were taken from venipuncture of the coccygeal vein or artery of the tail using a monoject tube (red cap $16 \mathrm{~mm} \times 100 \mathrm{~mm}$, Coviden, Mansfield, MA, USA). In order to assess the progesterone concentration and determine if the female had a functional Corpus luteum (defined as blood serum progesterone concentration greater than 1 $\mathrm{ng} / \mathrm{mL}$ ), blood samples were collected at day 9 , day 7, day 17 and day 45 (at this day ultrasonography of the ovarian structures were not assessed) [15]. Samples were centrifuged at $2000 \times \mathrm{g}$ for $20 \mathrm{~min}$ and the serum was stored at $-20^{\circ} \mathrm{C}$ for progesterone analysis. These tests were carried out in the endocrinology laboratory of the Veterinary School of the Universidad Nacional Autónoma de México. Serum concentrations of progesterone were determined through a solid phase RIA (Coat a Count ${ }^{\oplus}$, Diagnostic Products Corporation, Los Angeles, CA, USA). The bound fraction was quantified in a gamma radiation counter for $1 \mathrm{~min}$ and calculations were performed by means of the Riastat software. Assay sensitivity 
was $0.1 \mathrm{ng} / \mathrm{ml}$, while intra-assay variance coefficient was $3.33 \%$.

\section{Statistical Analysis}

Descriptive statistics (PROC MEANS procedure in SAS for windows version 9.4, SAS Institute, Cary, North Carolina, USA) was calculated for all the variables assessed in this experiment. Initial comparisons were performed between farms to determine the main effect of the farm and the treatment. No farm statistical significance effect was observed; therefore, the farms were pooled into their technological level. A general linear model (PROC GLM in SAS) with a $2 \times 3$ factorial arrangement, (two synchronization regimes, and three technological levels) was used to determine differences between BCS and dominant follicular diameter. Finally, to determine differences between binomial responses such as induction to resumption of ovarian activity and the display of sexual receptivity a logistic regression model was constructed using the PROC GLIMMIX procedure in SAS, the technology level of the farm and the treatment (either CIDR+EB or CIDR alone) were used as a fixed effect. Statistical difference among variables was established at $\alpha=0.05$. Results are presented as means \pm standard deviations.

\section{Results}

Overall, the proportion of cows that were in anestrus at the beginning of the experiment was similar across technological levels. However, by day 7 after implant withdrawal, the proportion of cows that resume ovarian activity detected by progesterone concentration $(>1 \mathrm{ng} / \mathrm{ml})$ increased in all technological level farms, no statistical main effect was observed within technological level, however, it was observed a significant effect of treatment $(\mathrm{P}=0.003)$ in technological level medium and low (Figure 1). Specifically, in the MT, out of the $44 \%$ of cows that were found to be cycling, $31 \%$ belonged to CIDR+EB and $17.24 \%$ to CIDR $(\mathrm{P}=0.04)$. Similarly, in the LT, out of the $34 \%$ of the cows that resume estrous cycles $6.2 \%$ were from CIDR treatment and $28.1 \%$ from CIDR+EB $(\mathrm{P}=0.03)$. By day 17 there was a significant main effect of technological level $(\mathrm{P}=0.05)$ on the proportion of animal that resumed the estrous cycles, but neither a main effect of treatment $(\mathrm{P}=0.97)$ nor an interaction between technological level and treatment $(\mathrm{P}=0.98)$. Furthermore, technological level of the farm showed a tendency $(\mathrm{P}=0.07)$ to affect that resume the estrous activity, a significant effect of treatment was observed $(\mathrm{P}=0.005)$ but no interaction between technological level and treatment (Figure 2).

The proportion of cows that showed estrus was different across technological level $(\mathrm{P}=0.02)$ (Figure 3$)$. The highest proportion of cows showing estrus regardless treatment was in the HT: $90 \%$ (40\% CIDR and 50\% CIDR+EB), MT: $50 \%(13.3 \% \mathrm{CIDR}$ and $36.7 \% \mathrm{CIDR}+\mathrm{EB})$ and in the LT: $50 \%(18.8 \% \mathrm{CIDR}$ and $31.3 \% \mathrm{CIDR}+\mathrm{EB})$.

The diameter of the dominant follicle was the time of the CIDR insertion was 


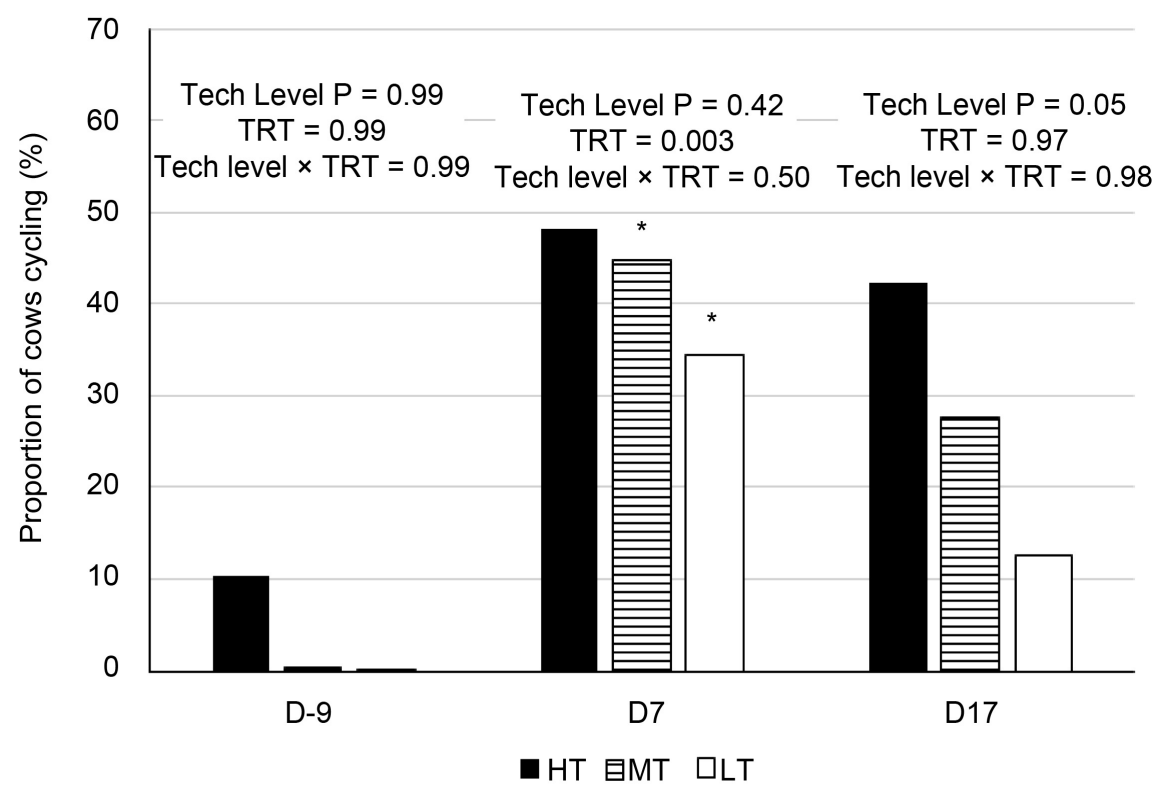

Figure 1. Proportion cows that resumed the estrous cycle across time and according to the different levels of technology at the farm (High technology $=$ HT, Medium technology $=$ MT and Low technology $=$ LT) included in the experiment. Day 9 was the day of CIDR insertion, CIDR lasted for 9 days, day 0 was the day of implant withdrawal.

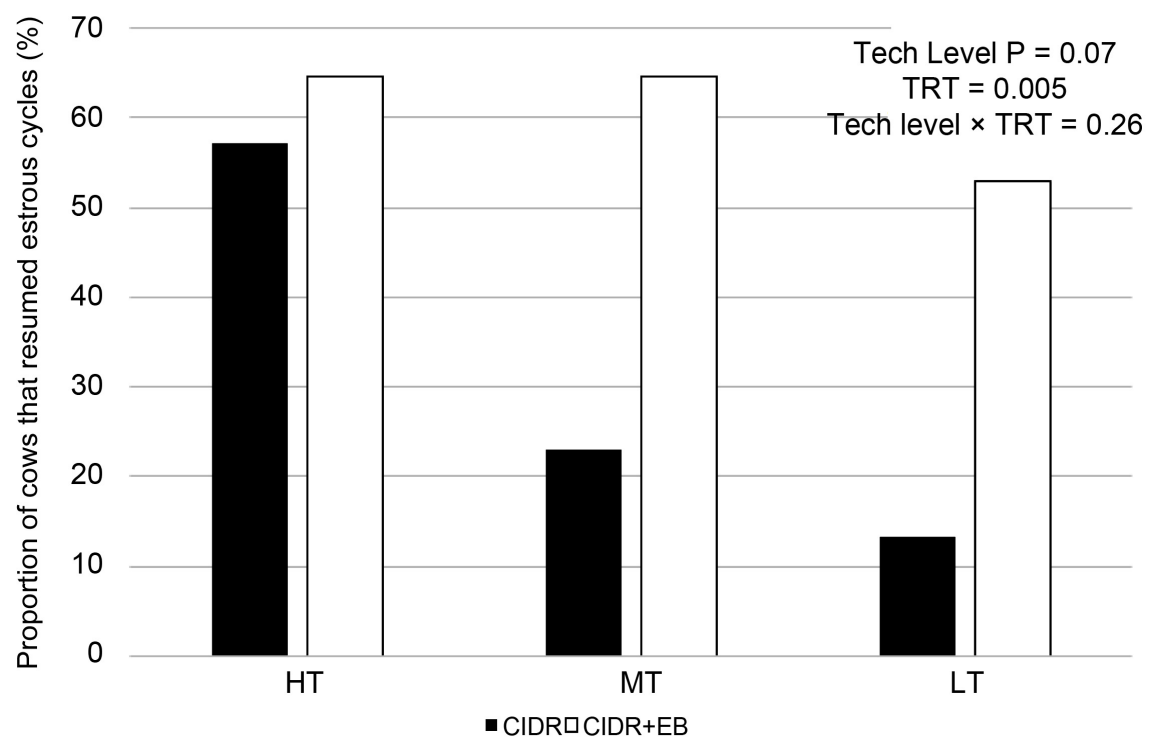

Figure 2. Proportion cows that resumed the estrous cycles at the end of the experiment (day 45) according to the different levels of technology at the farm (High technology = HT, Medium technology $=$ MT and Low technology $=$ LT) and according to the induction treatment received, all cows were treated with either a CIDR for 9 days with estradiol benzoate 24 hours after CIDR withdrawal (CIDR+EB) or alone (CIDR).

not different $(\mathrm{P}=0.37)$ among cows, HT: $11.06 \pm 4.85, \mathrm{MT}: 12.06 \pm 3.44$ and LT $10.65 \pm 4.91$. In terms of the body condition of the animals at the end of the experiment ( $\mathrm{d}$ 17) there was a significant difference between technological status, cows from HT had a higher BCS compared to cows in the MT and LT (Table 1). 


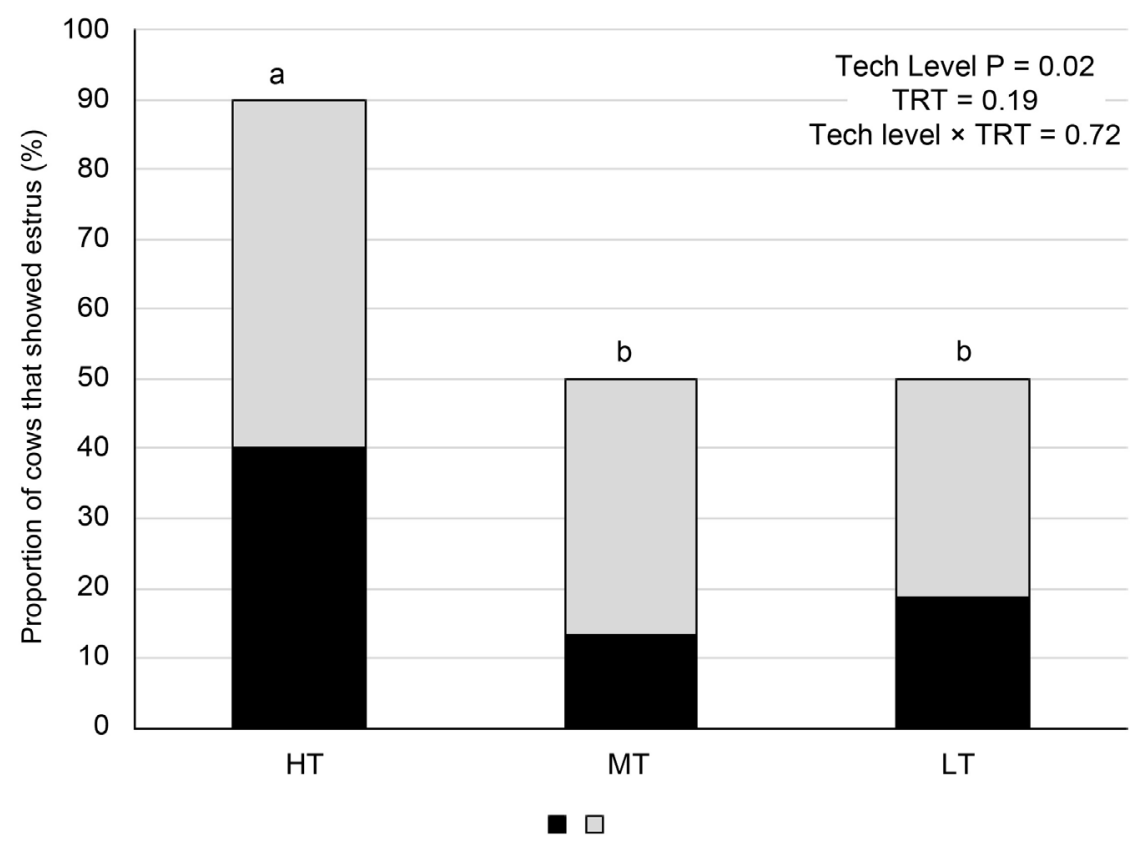

Figure 3. Proportion cows that showed estrus according to the different levels of technology at the farm (High technology $=$ HT, Medium technology $=$ MT and Low technology $=\mathrm{LT}$ ) and according to the induction treatment received, all cows were treated with either a CIDR for 9 days with estradiol benzoate 24 hours after CIDR withdrawal (CIDR+EB) or alone (CIDR).

\section{Discussion}

This experiment showed that the technological status of the farm affected the reproductive outcome of the hormonal treatment reflected in terms of proportion of cows that resumed the estrous cycle. Several reports have indicated that the scale of the farm impacts the productivity of the cattle [16] [17] due to feeding supply, health of the animals, breeding management and the genotype of the animals. Typically, producers in the tropical regions of the world faced a series of limitations that are reflected in the low productive and reproductive performance. In the present study, it was observed that a high proportion of cows at the beginning of the estrous induction program were in anestrus, just a small percentage of cows were cycling in the high technology status. This outcome is expected when working with females that have a low body condition score and bad genetics. Several authors have suggested that the intrinsic characteristics of the cows such as the age of the animal (between 5 and 7 years), the genetics, the number of parturitions and the fact that most of the cows are in a poor body condition. Score impedes the proper reproductive performance of the females. In the present study, it was observed that a low percentage of cows were cycling at the beginning of the hormonal induction due to the low body condition score and the fact that some of the animals were advanced in age and a low number of parturitions indicating possible fertility issues in these cows. In fact, several studies demonstrated that a cow with a poor body condition score struggles to resume the ovarian activity [18] [19], some reports suggest that females raised in 
tropical conditions can reinitiate the ovarian activity after 150 days postpartum or when the cow starts gaining body condition score [4] [20].

One of the most used approaches to induce the resumption of ovarian activity after calving in tropical cattle is the use of progestogens with or without the administration of estradiol benzoate [9]. Reproductive performance of females under this hormonal approach has been variable, some reports suggest that the estradiol benzoate could enhance the proportion of cows resuming the ovarian activity [21] [22] [23] and some other reports suggest that progesterone alone could enhance the reproductive response [24] [25]. In fact, [25] demonstrated that Bos indicus cattle receiving a progestogen and estradiol benzoate had a greater estrus response rate compared to the animals just receiving the progestogen, however, the ovulation rate was not affected by the treatment given to the cows. The present study compared the effect of CIDR alone or with the combination of $\mathrm{EB}$, and the technological status of the farm on the proportion of cows showing estrus and the percentage of animals that resume the ovarian activity. The proportion of cows showing estrus was greater in the HT (regardless of the hormonal induction treatment) compared to the other technological status. This study showed an increase in the proportion of active CL in the cows that received CIDR+EB seven days after the treatment (regardless the technological status) and cows that received CIDR+EB had a greater proportion of cows resuming the ovarian activity by day 45 across all technological levels. Similarly, [26] suggested that cows that received a progestogen with estradiol benzoate enhance the estrus response and ovulation. In the present experiment, it was observed an immediate effect (at day 7 and day 17) of the hormonal treatment on the number of animals that resume the ovarian activity. However, a significant difference was observed across technological status in the proportion of cows resuming the ovarian activity that received CIDR+EB. Increase of GnRH secretion is critical for the establishment of normal estrus cycles in postpartum animals Results from this study indicate that estradiol-induced LH surge was greater in ewes primed with progesterone, indicating the critical aspect of the cycle of progesterone and estradiol concentrations that occur during an estrous cycle. This finding reinforces the fact that although estradiol and progesterone have opposite actions, there is an intimate relationship between these hormones in regulation of $\mathrm{GnRH}$ secretion during the estrous cycle. In the present study, it was observed a positive effect of the CIDR+EB on the number of animals that resumed the ovarian activity by the end of the experiment ( 45 days).

Finally, one important aspect to consider is the technological status of the farm, which impacts directly the management of the animals. This study showed that small scale producers that have at least improved grazing systems, nutritional supplementation at the time of milking, annual preventive veterinary medicine programs and records of the animals had a greater reproductive response to the treatments. However, the CIDR+EB treatment also induced an increase of females that resumed the estrous cycles at day 45 in medium and low technological status suggesting the effect of the hormones. The adoption of 
technology such as hormonal induction of estrous cycles and artificial insemination on small scale producers has been low, and usually does not result in direct benefits to the producers due to complications in implementation, compliance to the protocols and the intrinsic characteristics of the cows such as age, genetics, nutritional conditions and general management of the farm [2] [11]. Another constraint in the transfer of technology to small-scale producers is the economic feasibility to target reproductive manipulations such as estrous synchronization that could be highly costly to the producers with often poor results [27]. Finally, it is important to acknowledge that this study is based on a low number of cows $(n=93)$ across farms with different technological status. However, the overall reproductive response was consistent within technological status of the farm suggesting a true physiological response to the hormonal induction program. Another potential limitation of this study is the variability of the farms due to the technological characteristics of the producers and the fact that the cows included in this study were not artificially inseminated, most of the producers on these conditions use bulls for the breeding program. Thus, it was not feasible to obtain an accurate estimation of the pregnancy rates and reproductive performance of the cows after the hormonal manipulation.

In conclusion, the combination of a progestogen and estradiol benzoate resulted in a high proportion of cows that were induced to resume the ovarian activity and this treatment was particularly beneficial in the medium and low technological status of the farms. Furthermore, it is necessary to assess the economic benefit of utilizing these treatments in relation to the pregnancy rates obtained.

\section{Conflicts of Interest}

The authors declare no conflicts of interest regarding the publication of this paper.

\section{References}

[1] Madan, M.L. (2005) Animal Biotechnology: Application and Economic Implications in Developing Countries. Revue Scientifique et Technique, 24, 127-139. https://doi.org/10.20506/rst.24.1.1555

[2] Bocquier, F. and González-García, E. (2010) Sustainability of Ruminant Agriculture in the New Context: Feeding Strategies and Features of Animal Adaptability into the Necessary Holistic Approach. Animal: An International Journal of Animal Bioscience, 4, 1258. https://doi.org/10.1017/S1751731110001023

[3] Producción pecuaria en América Latina y el Caribe. Organización de las Naciones Unidas para la Alimentación y la Agricultura. http://www.fao.org/americas/prioridades/produccion-pecuaria/es

[4] Galina, C.S. and Arthur, G.H. (1990) Review on Cattle Reproduction in the Tropics. Part 4. Oestrus Cycle. Animal Breeding Abstracts, 58, 697-707.

[5] Plasse, D., Warnick, A.C. and Koger, M. (1970) Reproductive Behaviour of Bos indicus Females in a Subtropical Environmental. IV. Length of Estrous Cycle, Duration of Estrus, Time of Ovulation, Fertilization and Embryo Survival in Grade 
Brahman Heifers. Journal of Animal Science, 30, 63-72. https://doi.org/10.2527/jas1970.30163x

[6] Vázquez-Selem, E., Aguilar-Barradas, U. and Villagómez-Cortés, J.A. (2016) Comparación de la eficiencia productiva y económica de grupos ganaderos organizados de doble propósito y de lechería familiar/semiespecializada. Ciencia Administrativa, 1, 226-237.

[7] Brar, P.S. and Nanda, A.S. (2008) Postpartum Ovarian Activity in South Asian Zebu Cattle. Reproduction in Domestic Animals, 43, 207-212. https://doi.org/10.1111/j.1439-0531.2008.01163.x

[8] Baruselli, P.S., Ferreira, R.M., Sá Filho, M.F. and Bó, G.A. (2018) Review: Using Artificial Insemination v. Natural Service in Beef Herds. Animal, 12, s45-s52. https://doi.org/10.1017/S175173111800054X

[9] Galina, C.S. and Orihuela, A. (2007) The Detection of Estrus in Cattle Raised under Tropical Conditions: What We Know and What We Need to Know. Hormones and Behavior, 52, 32-38. https://doi.org/10.1016/j.yhbeh.2007.03.025

[10] Bó, G.A., Baruselli, P.S. and Martínez, M.F. (2003) Pattern and Manipulation of Follicular Development in Bos indicus Cattle. Animal Reproduction Science, 78, 307-326. https://doi.org/10.1016/S0378-4320(03)00097-6

[11] Galina, C.S., Turnbull, F. and Noguez-Ortiz, A. (2016) Factors Affecting Technology Adoption in Small Community Farmers in Relation to Reproductive Events in Tropical Cattle Raised under Dual Purpose Systems. Open Journal of Veterinary Medicine, 6, 15-21. https://doi.org/10.4236/ojvm.2016.61003

[12] Montiel, F., Galina, C., Lamothe, C. and Castañeda, O. (2006) Follicular Dynamics, Ovulation Time and Pregnancy Rate in Bos taurus/Bos indicus Cows Induced to Cyclicity with Norgestomet in the Mexican Humid Tropic. Journal of Applied Animal Research, 29, 125-128. https://doi.org/10.1080/09712119.2006.9706586

[13] Sirois, J. and Fortune, J.E. (1988) Ovarian Follicular Dynamics during the Estrous Cycle in Heifers Monitored by Real-Time Ultrasonography. Biology of Reproduction, 39, 308-317. https://doi.org/10.1095/biolreprod39.2.308

[14] Ginther, O.J., Kastelic, J.P. and Knopf, L. (1989a) Composition and Characteristics of Follicular Waves during the Bovine Estrous Cycle. Animal Reproduction Science, 20, 187-200. https://doi.org/10.1016/0378-4320(89)90084-5

[15] Rajamahendran, R. and Taylor, C. (1990) Characterization of Ovarian Activity in Postpartum Dairy Cows Using Ultrasoud Imaging and Progesterone Profiles. Animal Reproduction Science, 22, 171-180. https://doi.org/10.1016/0378-4320(90)90058-N

[16] Onono, J.O., Wieland, B. and Rushton, J. (2013) Constraints to Cattle Production in a Semiarid Pastoral System in Kenya. Tropical Animal Health and Production, 45, 1415-1422. https://doi.org/10.1007/s11250-013-0379-2

[17] Duguma, B., Kechero, Y. and Janssens, G.P.J. (2012). Productive and Reproductive Performance of Zebu X Holstein-Friesian Crossbred Dairy Cows in Jimma Town, Oromia, Ethiopia. Global Veterinaria, 8, 67-72.

[18] D’Occhio, M.J., Baruselli, P.S. and Campanile, G. (2019) Influence of Nutrition, Body Condition, and Metabolic Status on Reproduction in Female Beef Cattle: A Review. Theriogenology, 125, 277-284.

https://doi.org/10.1016/j.theriogenology.2018.11.010

[19] Montiel, F. and Ahuja, C. (2005) Body Condition Score and Suckling as Factors Influencing the Duration of Postpartum Anestrus in Cattle: A Review. Animal Re- 
production Science, 85, 1-26. https://doi.org/10.1016/j.anireprosci.2003.11.001

[20] Anta, E., Rivera, J.A., Galina, C.S., Porras, A., Zarco, L. and Russell, J.M. (1989) Análisis de la información publicada en México sobre eficiencia reproductiva de los bovinos I. Estudio bibliométrico. Veterinaria México, 20, 3-10.

[21] Ayres, H., Martins, C.M., Ferreira, R.M., Mello, J.E., Dominguez, J.H., Souza, A.H., Valentin, R., Santos, I.C. and Baruselli, P.S. (2008) Effect of Timing of Estradiol Benzoate Administration upon Synchronization of Ovulation in Suckling Nelore Cows (Bos indicus) Treated with a Progesterone-Releasing Intravaginal Device. Animal Reproduction Science, 109, 77-87. https://doi.org/10.1016/j.anireprosci.2007.12.001

[22] Sales, J.N., Carvalho, J.B., Crepaldi, G.A., Cipriano, R.S., Jacomini, J.O., Maio, J.R., Souza, J.C., Nogueira, G.P. and Baruselli, P.S. (2012) Effects of Two Estradiol Esters (Benzoate and Cypionate) on the Induction of Synchronized Ovulations in Bos indicus Cows Submitted to a Timed Artificial Insemination Protocol. Theriogenology, 78, 510-516. https://doi.org/10.1016/j.theriogenology.2012.02.031

[23] Sá Filho, M.F., Baldrighi, J.M., Sales, J.N., Crepaldi, G.A., Carvalho, J.B., Bó, G.A. and Baruselli, P.S. (2011) Induction of Ovarian Follicular Wave Emergence and Ovulation in Progestin-Based Timed Artificial Insemination Protocols for Bos indicus Cattle. Animal Reproduction Science, 129, 132-139.

https://doi.org/10.1016/j.anireprosci.2011.12.005

[24] Fetter, P.H., Galina, C.S., Pulido, A.R., Orihuela, A. and Maquivar, M. (2006) A Note on Estrous Response in Cows Induced with or without the Application of Estrogens, and Their Effect in Nontreated Herdmates. Journal of Veterinary Behavior, 1, 75-79. https://doi.org/10.1016/j.jveb.2006.08.001

[25] Solano, J., Orihuela, A., Galina, C.S. and Montiel, F. (2000) Sexual Behavior of Zebu Cattle (Bos indicus) Following Estrous Induction by Syncro-Mate B, with or without Estrogen Injection. Physiology \& Behavior, 71, 503-508. https://doi.org/10.1016/S0031-9384(00)00367-X

[26] Maquivar, M., Galina, C.S. and Orihuela, A. (2002) Cows Treated with Synchromate B May Cluster Their Sexual Behavior Independent of Follicular Growth at the Time of Oestrus. Physiology \& Behavior, 76, 199-203. https://doi.org/10.1016/S0031-9384(02)00701-1

[27] Sánchez, Z., Lammoglia, M.A., Alarcón, M.A., Romero, J.J. and Galina, C.S. (2015) Is the Production of Embryos in Small-Scale Farming an Economically Feasible Enterprise? Reproduction in Domestic Animals, 50, 574-579.

https://doi.org/10.1111/rda.12526 